Article

\title{
A Sightseeing Spot Recommendation System That Takes into Account the Change in Circumstances of Users
}

\author{
Yuri Mizutani ${ }^{1}$ and Kayoko Yamamoto ${ }^{2, *}$ \\ 1 Faculty of Informatics and Engineering, University of Electro-Communications, Chofu 182-8585, Japan; \\ yuu1214.uec@gmail.com \\ 2 Graduate School of Informatics and Engineering, University of Electro-Communications, \\ Chofu 182-8585, Japan \\ * Correspondence: k-yamamoto@is.uec.ac.jp; Tel.: +81-42-443-5728
}

Received: 14 September 2017; Accepted: 12 October 2017; Published: 15 October 2017

\begin{abstract}
The present study aimed to design, develop, operate and evaluate a sightseeing spot recommendation system for urban sightseeing spots in order to support individual, as well as group sightseeing activities while taking into consideration the user's needs, which can change according to the circumstances (each user's important conditions and sightseeing unit). The system was developed by integrating Web-GIS (Geographic Information Systems), the pairing system, the evaluation system, as well as the recommendation system into a single system, and it was also connected with external SNS (Social Networking Services: Twitter and Facebook). Additionally, the system was operated for four weeks in the central part of Yokohama City in Kanagawa Prefecture, Japan, and the total number of users was 52. Based on the results of the web questionnaire survey, the usefulness of the system when sightseeing was high, and the recommendation function of sightseeing spots, which is an original function, has received mainly good ratings. From the results of the access analysis of users' log data, it is evident that the system has been used by different types of devices, just as it was designed for, and that the system has been used according to the purpose of the present study, which is to support the sightseeing activities of users.
\end{abstract}

Keywords: sightseeing spot recommendation system; Web-GIS (Geographic Information Systems); pairing system; evaluation system; recommendation system; SNS (Social Networking Service); circumstances of users

\section{Introduction}

In the advanced information-oriented society of Japan in recent years, various information is transmitted via the Internet and is easily sent, received or shared using information systems that can be used "anytime", "anywhere" and "by anyone". Additionally, with the spread of SNS (Social Networking Services), the flood of information on the Internet has sped up. Information related to tourism can also be obtained through the Internet in addition to conventional methods such as magazines and guidebooks. The Internet has become the main source of information when planning a sightseeing trip or searching for information concerning sightseeing spots. However, due to the quantity and variety of information available, it has become difficult to select and obtain suitable information according to the users' needs. As there is an especially large amount of information submitted and released concerning sightseeing spots in urban areas, which makes it difficult for those with limited knowledge or a sense of locality to efficiently obtain the necessary information, the need for a recommendation system to help users find suitable information is becoming greater.

On the other hand, though there are important conditions when deciding on a location to visit, such conditions are not always the same and may change according to the circumstances. Additionally, 
when sightseeing with a group, the issue is how to suitably reflect the preferences of each member of the group when deciding on where to visit. Based on the background mentioned above, the present study aims to develop a sightseeing spot recommendation system for urban sightseeing spots in order to support individual, as well as group sightseeing activities while taking into consideration the user's needs, which can change according to the circumstances. The circumstances of the users is defined as the important conditions and sightseeing unit (individuals or groups). More specifically, the present study will design and develop a system that is an integration of Web-GIS, the pairing system, the evaluation system and the recommendation system. Furthermore, the operation and evaluation of the developed system will be conducted, and improvement measures will be extracted.

Regarding the operation target area, the central part of Yokohama City in Kanagawa Prefecture, Japan, was selected. One reason for this selection is that it has many tourists visit, as it is a popular urban sightseeing area, and that it is difficult for tourists to efficiently obtain information due to the large amount of information submitted and released. The second is that sightseeing spots can be recommended according to the user preferences using the system, as there is a variety of sightseeing spots.

\section{Related Work}

The system in the present study was developed by integrating multiple systems such as Web-GIS, the pairing system, the evaluation system, as well as the recommendation system into a single system, and it was also connected with external SNS. Therefore, the present study is related to three fields of study, namely: (1) studies regarding tourism support systems and methods; (2) studies regarding recommendation systems and methods for sightseeing spots; and (3) studies regarding social media GIS.

For (1), studies regarding tourism support systems and methods, Ishizuka et al., 2007 [1], proposed a similarity search method for the movement tracking data of tourists obtained from their location data and text information. Kurata, 2012 [2], developed an automatic generation system for sightseeing courses using Web-GIS and GA (Genetic Algorithm). Kawamura, 2012 [3], proposed the use of standard tags related to sightseeing on SNS and set up a website to organize tourism information of Hokkaido on the Internet. Sasaki et al., 2013 [4], gathered information concerning local resources and developed a system that supports the sightseeing activities of each user. Fujitsuka et al., 2014 [5], used the pattern mining method, which lists and extracts the time series action when touring sightseeing spots, and developed an outing plan recommendation system. Ueda et al., 2015 [6], generated post-activity information from the sightseeing activities of the users and developed a tourism support system that shares such information as prior information for other users. Okuzono et al., 2015 [7], took into consideration the preferences of several people using photos and proposed a system that recommends sightseeing spots. Fujita et al., 2016 [8], developed a navigation system using AR (Augmented Reality), Web-GIS and social media, in order to support sightseeing activities during normal occasions and evacuations in case of a disaster.

For (2), studies regarding recommendation systems and methods for sightseeing spots, Kurashima et al., 2011 [9], as well as Canneyt et al., 2011 [10], proposed a travel route recommendation system and a sightseeing spot recommendation system, respectively, using geotags from picture-sharing sites. Batet et al., 2012 [11], developed a recommendation system of sightseeing spots using the multi-agent system. Uehara et al., 2012 [12], extracted tourism information from the Internet, calculated the similarity between sightseeing spots from several feature vectors and developed a system that recommends sightseeing spots. Shaw et al., 2012 [13], took into consideration the location information and visit history of the users and developed a system that presents a list of sightseeing spots near the user. Zhou et al., 2016 [14], developed a sightseeing spot recommendation system using AR, Web-GIS and SNS.

Additionally, studies related to POI (Point-Of-Interest) recommendations among studies related to LBSN (Location-Based Social Networks) are also included in the same field of the present study. 
Representative examples include the POI recommendation system by Yu et al., 2009 [15], which supports travel planning, the POI recommendation system by Noguera et al., 2012 [16], which is based on current location information, and the POI recommendation system proposed by Baltrunas et al., 2011 [17], which is based on location information and user preference. Ye et al., 2011 [18], and Ying et al., 2012 [19], proposed a POI recommendation system that is based on location information and user preferences, as well as social networks. Bao et al., 2013 [20], also proposed a recommendation system. Yuan et al., 2013 [21], proposed a POI recommendation method that takes into consideration time and space, while Liu et al., 2013 [22], proposed a POI recommendation method that takes into consideration the changes in user preferences.

For (3), studies regarding social media GIS, Yanagisawa et al., 2011 [23], as well as Nakahara et al., 2012 [24], developed an information sharing GIS, using Web-GIS, SNS and Wiki, with the purpose of storing and sharing information of the local community. Yamada et al., 2013 [25], and Okuma et al., 2013 [26], developed a social media GIS that strengthened the social media function of the information sharing GIS mentioned above. Based on such systems developed from preceding studies, Murakoshi et al., 2014 [27], and Yamamoto et al., 2015 [28], developed a social media GIS supporting the continuous use of disaster information during normal occasions and in case of a disaster. Additionally, based on these social media GIS, Ikeda et al., 2014 [29], developed a social recommendation GIS to accumulate sightseeing spot information and to recommend sightseeing spot information according to the preferences of each user.

Such preceding studies of (1), (2) and (3) do not meet the needs of users while sightseeing, which change according to the circumstances, and cannot sufficiently support actual sightseeing activities. Most of the systems in the above preceding studies were developed as the tools for information gathering before sightseeing. Additionally, excluding the study by Okuzono et al., 2015 [7], the preceding studies of (1) and (2) target individuals for recommendations and do not consider the possibility of sightseeing as a group. More specifically, these preceding studies do not consider combining the preference information of each individual within the group and recommending the information that meets the preferences of the whole group. Furthermore, though Okuzono et al., 2015 [7], considered groups as recommendation targets, because users are categorized by their preferences using photos, there is a possibility of sightseeing spots that do not meet the user preferences being displayed.

Moreover, in order to verify the usefulness of the system in the present study, we perform a comparison of features with existing services such as 4travel.jp [30], KAYAK [31] and TripAdvisor [32]. These services are systems that also allow users to make word-of-mouth submissions about sightseeing spots. However, their support for tourist trips is limited to displaying and introducing sightseeing spot information on the digital maps of the Web-GIS and recommending facilities and spots near places chosen by users. They do not take the preferences of each user into account when recommending sightseeing spots.

Therefore, against the above-mentioned existing services, the system recommends sightseeing spots considering the preferences of each user in detail. Furthermore, in addition to meeting the changing needs of users while sightseeing, referring to distance-adjusted covariates proposed by Ohki et al., 2013 [33], the present study will demonstrate the individuality in recommending sightseeing spots targeting not only individuals, but also groups.

\section{System Design}

\subsection{System Characteristics}

In order to implement several unique functions as described in detail in Section 4.1 in response to the aim of the present study, the system is made up of Web-GIS, the pairing system, the evaluation system, as well as the recommendation system, and it is also connected with external SNS (Twitter and Facebook), as shown in Figure 1. The system aims to support individual or group sightseeing 
activities, and by combining the preference information of each individual within the group using the pairing system, information that meets the preferences of the whole group can be recommended. Additionally, when recommending sightseeing spots, by selecting priority conditions, information that the user may need can be preferentially displayed. By evaluating sightseeing spots that users have visited, sightseeing spot information can be also updated. In this way, evaluation results can aid the improvement in the accuracy of the recommendation system. Furthermore, by connecting with external SNS sites, the simplification of user registration and login, as well as the acquisition of real-time sightseeing spot information can be realized. Regarding Facebook, with the purpose of expanding the user class, the sharing function for sightseeing spot information on Facebook was installed. In this way, by means of a system that takes into consideration the changes of prioritized conditions concerning sightseeing spots, as well as the differences in preferences within a group, sightseeing activity support can be realized.

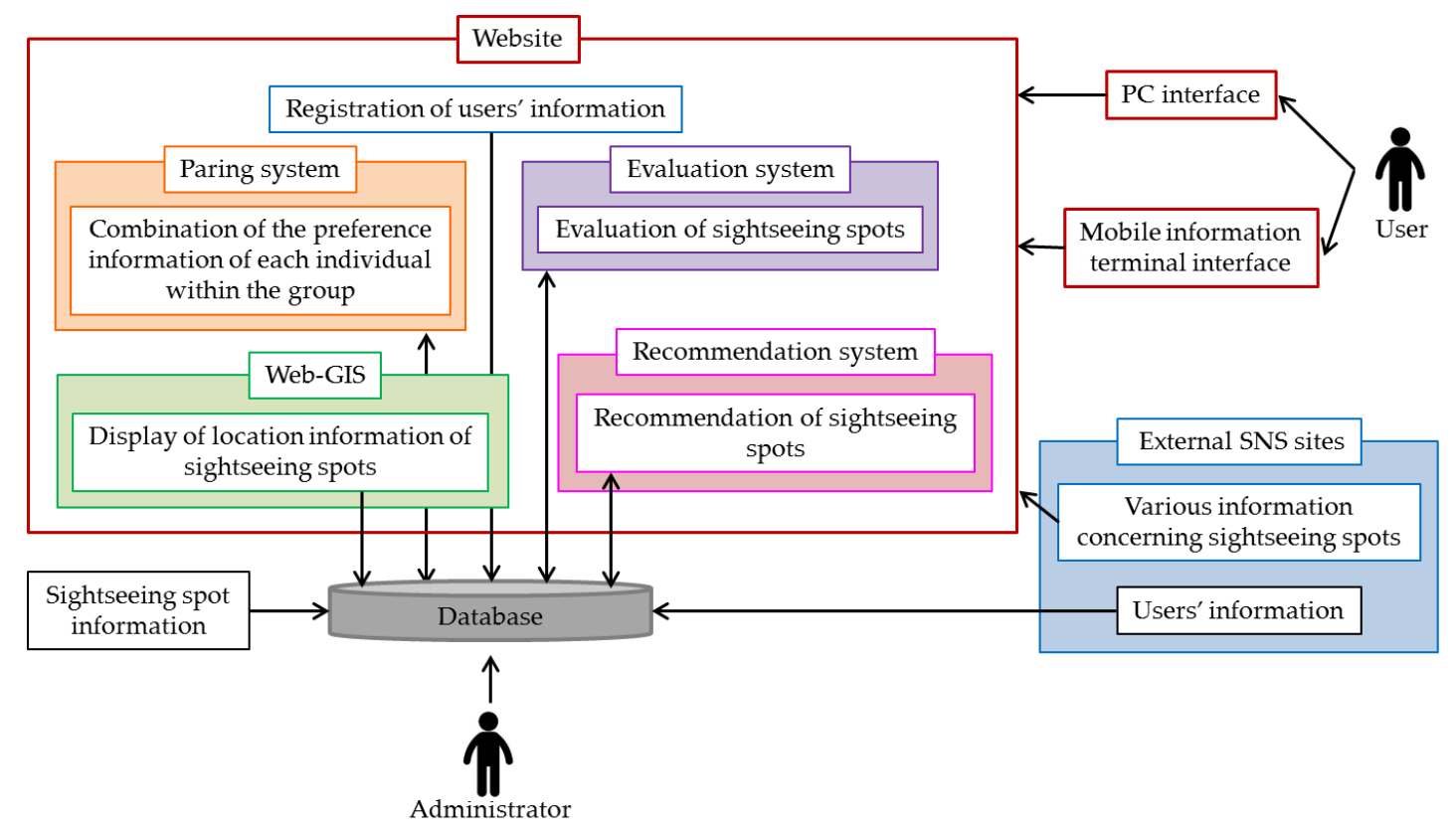

Figure 1. System design.

\subsection{Target Information Terminals}

Though the system is meant to be used from PCs or mobile devices, as there is no difference in functions on different information terminals, the same function can be used from any device. PCs are assumed to be used indoors for gathering information or evaluating sightseeing spots. On the other hand, mobile devices are assumed to be used both indoors and outdoors to gather information concerning sightseeing spots.

\subsection{System Operation Environment}

The system operates using the web server, database server and the GIS server. Figure 2 shows the operating environment of the system. The web server and database server both use Heroku, which is a PaaS provided by the Salesforce company. For the GIS server, ArcGIS Online was used. The web application developed with the system was implemented using PHP and JavaScript. 


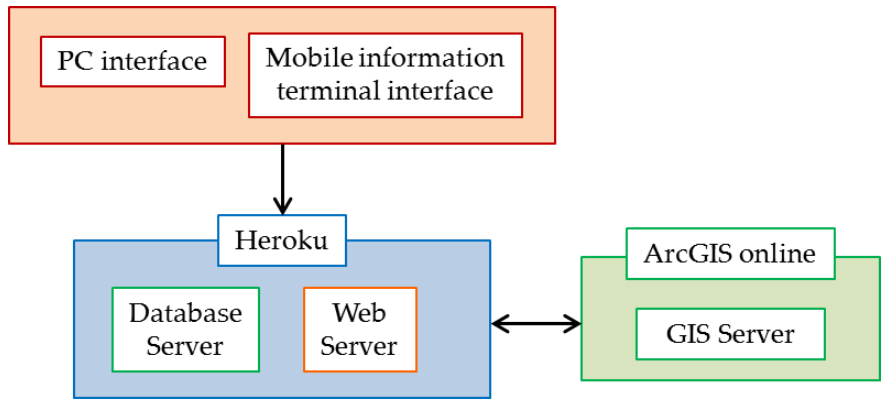

Figure 2. System operating environment.

\subsection{Design of Each System}

\subsubsection{Web-GIS}

As there are a variety of Web-GIS types, it is necessary to select the most suitable type according to the purpose of using the system. In terms of convenience, the system should be used without having to download any special software, which would be inconvenient for users, and it would be desirable if it could be used by accessing the Website on any PC or mobile device connected to the Internet. Therefore, when displaying the location information of a sightseeing spot recommended to the users, the ArcGIS API for JavaScript by ESRI was used. Additionally, regarding the viewing function of sightseeing spot information (see Section 4.1), layers were developed by loading the sightseeing spot information on ArcGIS Online from the same company, and this was overlaid on the digital road maps. By importing the created digital maps onto the website, it becomes easier to switch layers to enhance the convenience for users.

\subsubsection{Pairing System}

As the support for group sightseeing activities is the main purpose of the system, a pairing system that can reflect the preferences of each user within a group is needed. By using the method mentioned below, the pairing system can reflect the preferences of all users in a group and create preference information for the whole group.

First, it is necessary to create the preference information for each individual. The preference information can be entered by evaluating items concerning preferences on a scale of $1-5$. Next, in order to create the preference information for the whole group, it is necessary to link the information of each user together (group registration). The system has made it easy to register a group as each user is given a user number, and a user wishing to register a group can register all users within a group by entering their numbers in the corresponding items. Then, by using the pairing system, the variation in preferences within the group can be reflected, and the preference information as a group can be created.

As the decision-making method used in the pairing system, the distance-adjusted covariates proposed by Ohki et al., 2013 [33], was adopted. Distance-adjusted covariates remove (narrow) the range of individual opinions within the group and determine a rank that equalizes the range in opinions among a group (Ohki et al., 2013) [33]. For individual evaluations, the higher the rating is, the closer it gets to the opinions of the whole group, and the lower the rating is, the further it gets from the opinions of the group. By weighing the importance of individual evaluations using such a rating system, a group opinion that everyone in the group agrees on can be produced. The definition of the distance-adjusted covariates is as shown below.

First, the sum of VDI (Variety Dispersion Index) of the variations within the group is defined as follows.

$$
\sum_{p=1}^{n} r^{(p)}=1
$$




$$
\begin{gathered}
D_{k}^{(p)}=\sqrt{\sum_{i=1}^{n}\left(x_{k}^{(p)}-x_{k}^{(i)}\right)^{2}}+\frac{1}{n} \sum_{i=1}^{n}\left|x_{k}^{(i)}\right| \\
e_{k}=\frac{1}{n} \sum_{p=1}^{n}\left(r^{(p)} D_{k}^{(p)}\right) \\
\text { VDI }=\sum_{k=1}^{m} \sum_{p=1}^{n}\left(r^{(p)} D_{k}^{(p)}-e_{k}\right)^{2}
\end{gathered}
$$

$p, i \in\{1,2, \ldots, n\}:$ decision maker

$k \in\{1,2, \ldots, m\}:$ evaluation items

$r^{(p)}$ : weight value of individual $p$

$x_{k}^{(p)}$ : evaluation results for evaluation item $k$ by individual

$D_{k}^{(p)}$ : difference of opinions between individual $p$ and others concerning evaluation item $k$ $e_{k}$ : arithmetic mean of the rated $D_{k}^{(p)}$

Referring to Okuzono et al., 2007 [7], the decision makers within the definition of the distance-adjusted covariates will be considered as a user in a group and the evaluation results as the preference value. Next, the weight value that minimizes the VDI will be calculated using the Lagrange multiplier method. The equations used are as shown in (5) and (6).

$$
\begin{gathered}
D^{(p)}=\left[\begin{array}{c}
D_{1}^{p} \\
D_{2}^{p} \\
\vdots \\
D_{m}^{p}
\end{array}\right], r^{*}=\left[\begin{array}{c}
r^{(1) *} \\
r^{(2) *} \\
\vdots \\
r^{(n) *}
\end{array}\right] \\
{\left[\begin{array}{c}
r^{*} \\
\lambda
\end{array}\right]=\left[\begin{array}{ccccc}
(n-1)\left|D^{(1)}\right|^{2} & -\left(D^{(1)}, D^{(2)}\right) & \ldots & -\left(D^{(n)}, D^{(1)}\right) & 1 \\
-\left(D^{(2)}, D^{(1)}\right) & (n-1)\left|D^{(2)}\right|^{2} & \ldots & -\left(D^{(n)}, D^{(2)}\right) & 1 \\
\vdots & \vdots & \ddots & \vdots & \vdots \\
-\left(D^{(n)}, D^{(1)}\right) & -\left(D^{(n)}, D^{(2)}\right) & \ldots & (n-1)\left|D^{(n)}\right|^{2} & 1 \\
1 & 1 & \ldots & 1 & 0
\end{array}\right]\left[\begin{array}{c}
0 \\
0 \\
\vdots \\
0 \\
1
\end{array}\right]}
\end{gathered}
$$

\section{$\lambda$ : Lagrange multiplier}

Then, for each evaluation item, the sum of the preference value of each user in a group multiplied by the calculated weight value $r$ will be the preference value of the group. The equation used to calculate the group preference value for evaluation item $k$ is as shown in (7).

$$
E_{k}=\sum_{i=1}^{n} r^{(i)} x_{k}^{(i)}
$$

$E_{k}$ : group preference value concerning evaluation item $k$

\subsubsection{Evaluation System}

In the system, existing evaluation values and the evaluation values through the user review are combined using the evaluation system, and the evaluation values for sightseeing spots that are used in the recommendation system are recalculated. By doing so, the accuracy of the recommendation system is improved. The use of the distance-adjusted covariates, which was used in the pairing system mentioned in the previous section, is preferred as the recalculation method for evaluation values. However, as the number of users making evaluations becomes greater and the amount of 
calculations increase, delays or server breakdowns may occur due to system overload. Therefore, for each of the eight evaluation items (satisfaction level, access, non-crowdedness, accessibility for those with special needs, cost effectiveness, atmosphere, amenity and recommendation degree), taking into consideration the number of users who evaluate, the arithmetic mean of evaluation values of sightseeing spots accumulated in the database and the evaluation values of sightseeing spots entered by users is calculated, and a new evaluation value is produced.

\subsubsection{Recommendation System}

According to Jannach et al., 2011 [34], and Kamishima, 2008 [35], the recommendation methods for recommending information that meets the user preferences from large information groups include the collaborative recommendation, content-based recommendation and the knowledge-based recommendation. The knowledge-based recommendation will be used for the recommendation system in the present study. This is selected to solve the cold-start problem. The cold-start problem is where there is a lack of information that can be offered to users and suitable recommendations cannot be made. In order to solve this issue, the system creates preference information by explicitly asking for the preferences of users in advance and uses the knowledge-based recommendation to make recommendations. This recommendation method is designed to be used in the system. When each user registers at first, he/she is asked to rank the eight evaluation items (satisfaction level, access, non-crowdedness, accessibility for those with special needs, cost effectiveness, atmosphere, amenity and recommendation degree, which are the same evaluation items of the evaluation system mentioned in the previous section) on five levels, and the preference information is created. This is set as the user's feature vector, while the evaluation value (evaluation information) created by the evaluation system in the previous section is set as the feature vector of sightseeing spots, and the degree of similarity between these values is calculated using Equation (8).

$$
\operatorname{Sim}_{j}=\frac{\sum_{i=1}^{n} U_{i} \times S_{i j}}{\sqrt{\sum_{i=1}^{n}\left(U_{i}\right)^{2}} \times \sqrt{\sum_{i=1}^{n}\left(S_{i j}\right)^{2}}}
$$

$\operatorname{Sim}_{j}:$ degree of similarity

$U_{i}:$ preference as a group

$S_{i j}$ : evaluation of sightseeing spots

Afterwards, the feature vectors of the top 20 sightseeing spots in the order of the highest degree of similarity are obtained, and from the evaluation items used when creating the user preference information, the top 10 sightseeing spots with the highest values concerning priority evaluation items are recommended to users.

\section{System Development}

\subsection{The Frontend of the System}

The system will implement unique functions for users, which will be mentioned below, in response to the aim of the present study, as mentioned in Section 1. In order to implement these several unique functions, the system was developed by integrating multiple systems into a single system, and it was also connected with external SNS.

(1) Login function connected to external SNS:

Before logging in to the system, by clicking on the "login and sign up" button in the menu bar at the top of the screen or on the link under "your information" in the sidebar on the left of the screen, users can move to the login page. If users click on the Facebook or Twitter icon under "connect to SNS" and allow access to their SNS information, user registration will be complete. Next, by going to the "my page" screen, users can enter their information and preferences. 
(2) Group registration function:

After logging in to the system, users can go to the group register page by clicking on "my page" in the menu bar at the top of the screen followed by the "register and edit group" under "menu items of my page. Sightseeing groups can be registered on this page. The membership number that was given to each user is needed when registering a group. After entering the number of other users in the applicable category such as "family", "partner and spouse", "friends group 1" and "friends group 2", users can press "register".

(3) Viewing function of sightseeing spot information:

After logging in to the system, users can go to the viewing page for sightseeing spot information by clicking on the "view sightseeing spots" in the menu bar. Figure 3 shows the pages for the viewing function of sightseeing spot information. On the sightseeing spot search page shown on the left page of Figure 3, searches can be made using either "search category" or "search on map". In case of the former, when users choose a category, a list of sightseeing spots within that category will be displayed shown on the middle page of Figure 3. If users choose a sightseeing spot name from the list, they can view the details on that sightseeing spot. In the case of the latter, a marker colored differently according to its category will be shown on the digital map of the Web-GIS. By clicking on the icon at the top left of the screen, explanatory notes can be displayed, and users can also choose to display and hide the markers. When the marker is clicked on, as shown on the right page of Figure 3, a popup containing the "name of the sightseeing spot", "category" and "details link" will be displayed. By clicking on "details link", users can view detailed information concerning sightseeing spots.

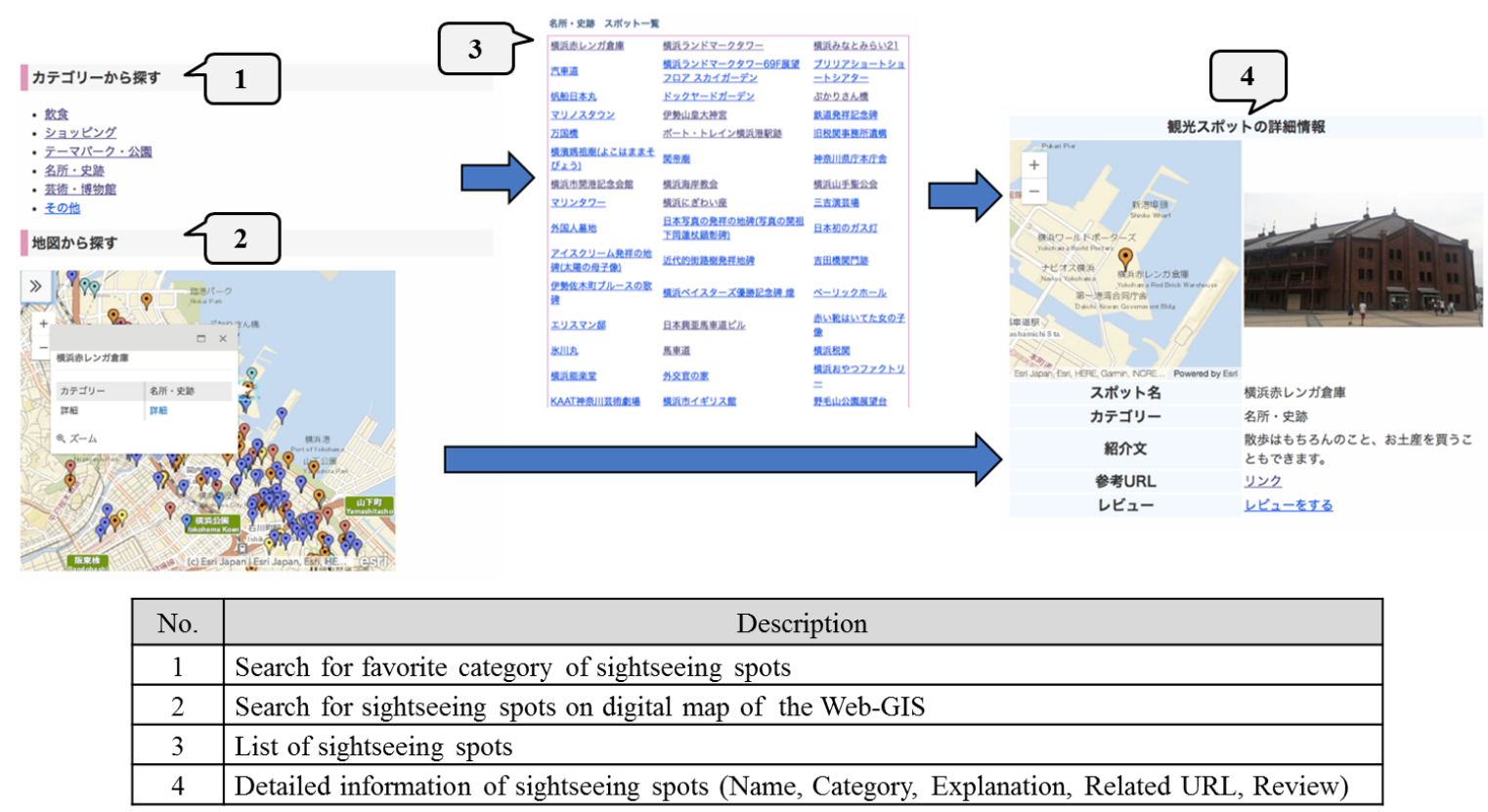

Figure 3. Pages for the viewing function of sightseeing spot information.

(4) Evaluation function of sightseeing spots:

By clicking on "write a review" in the items displayed on the page with details on sightseeing spots, users will be moved to the review page for sightseeing spots. Figure 4 shows the page for the evaluation function of sightseeing spots. On this page, users can review and evaluate sightseeing spots they have visited. Users will conduct a five-grade evaluation concerning eight evaluation items, and the review will be submitted by clicking on "submission". The answers are designed not to overlap. 


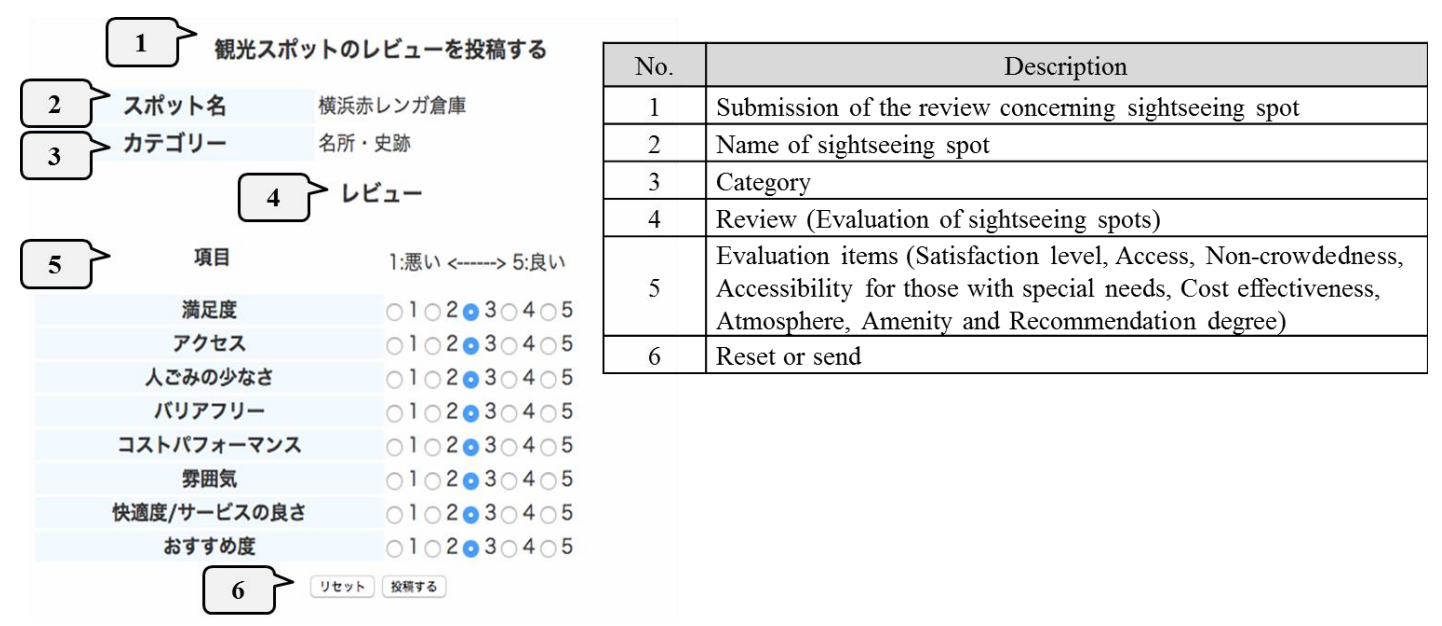

Figure 4. Page for the evaluation function of sightseeing spots.

(5) Recommendation function of sightseeing spots:

After logging in to the system, users can go to the sightseeing spot recommendation page by clicking on "sightseeing spot recommendations" in the menu bar. Figure 5 shows the pages for the recommendation function of sightseeing spots. On the sightseeing spot recommendation page as shown on the right side of Figure 5, users can select a "sightseeing group" and "sightseeing spot category", as well as "priority evaluation items", and click on "send". Then, on the right page of Figure 5, the list of recommended sightseeing spots will appear, and the location information will be displayed on the digital map of the Web-GIS. As with the "search on map" of the viewing function of sightseeing spot information, a popup containing the "name of the sightseeing spot", "category" and "details link" will be displayed when clicking on the markers within the map. Users can go to the detailed information page on sightseeing spots by clicking on "details link" in the popup or the link shown in the list of sightseeing spots. Additionally, on the display screen for recommendation results, the "group", "category" and "priority evaluation items", which were selected when using the recommendation function of sightseeing spots, will be displayed on the left side of the screen, while explanatory notes concerning the markers will be displayed on the digital map of the Web-GIS.

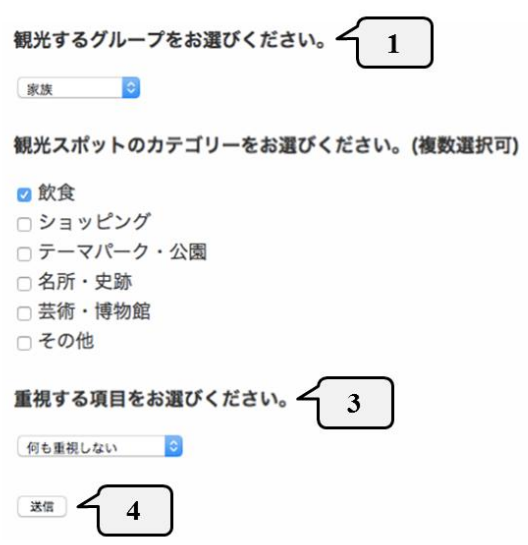

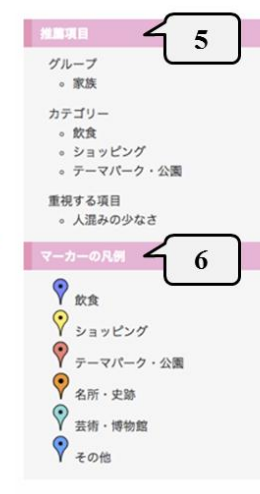

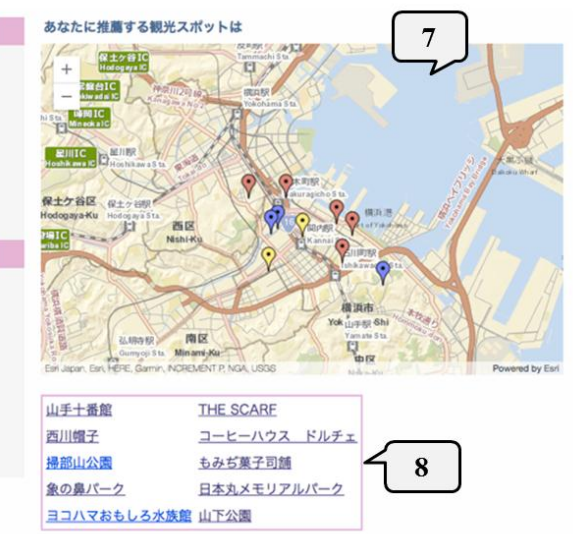

Figure 5. Cont. 


\begin{tabular}{|c|l|}
\hline No. & \multicolumn{1}{|c|}{ Description } \\
\hline 1 & Select sightseeing group \\
\hline 2 & Select sightseeing spot category \\
\hline 3 & Select priority evaluation items \\
\hline 4 & Send \\
\hline 5 & Recommendation results \\
\hline 6 & $\begin{array}{l}\text { Legend of marker for sightseeing spot category ("food and drink", "shopping", "amusement parks } \\
\text { and parks", "famous and historical sights", "art and historic museums" and "others (events, etc.)" }\end{array}$ \\
\hline 7 & Recommended sightseeing spots on the digital map of the Web-GIS \\
\hline 8 & List of Recommendation sightseeing spots \\
\hline
\end{tabular}

Figure 5. Pages for the recommendation function of sightseeing spots.

\subsection{The Backend of the System}

(1) Member registration and login processes linked with SNS:

The login function connected to the external SNS was created using the Twitter OAuth library made for developers in the case of Twitter and the "Facebook login" made for Facebook developers in the case of Facebook. Regarding registration of user information and login, the hash value of the internal management parameter, obtained through callback when the user allows access to SNS information, is generated using the hash function of PHP. A search through the database for this value will be conducted, and the login process will start if there is a match. If there is no match, the hash value will be accumulated in the database in order to register the user. Moreover, in the case of Facebook, as "gender" and "age" are contained in the information obtained through callback, these are also accumulated in the database in order to lessen the burden on the users.

(2) Pairing process between users:

In the preceding studies introduced in Section 2, users can receive sightseeing spot recommendations that meet individual preferences from the system by registering their own preferences. However, in the system, sightseeing activities for individuals, as well as groups are supported. Therefore, in the system, by combining the preferences of all users within a group registered at the frontend, the process of calculating the group preference will be conducted at the backend. The conceptual diagram concerning this process is as shown in Figure 6.

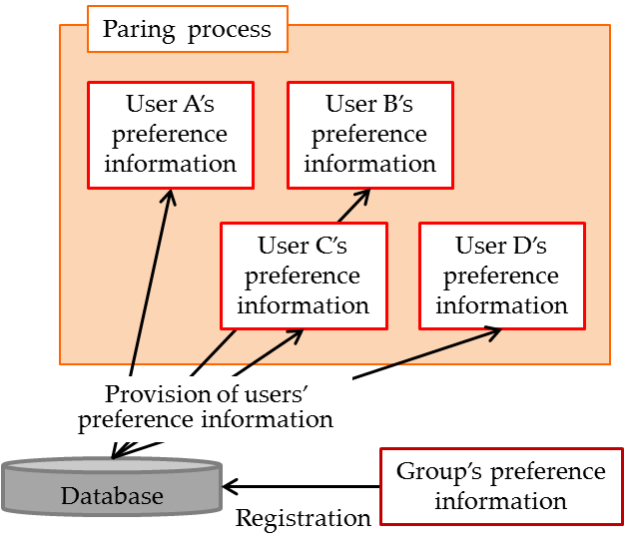

Figure 6. Pairing process.

When a user registers a group (connecting users), the preference information of connected users is taken from the user information accumulated in the database, and the group preference is calculated by combining the information according to the process described in Section 3.4.2. By accumulating this in the database, recommendations for when a group is registered can be received. 
(3) Process concerning the evaluation function of sightseeing spots:

In order to make the recommended sightseeing spots in the system closer to the preferences of a user, the system has users write a review on sightseeing spots they have visited, and a calculation process of this new evaluation value is conducted at the system backend. Evaluation values from the sightseeing spot data, which are accumulated in the database, are imported, and using this, as well as the evaluation values obtained from user reviews, new evaluation values are calculated and the values in the database updated.

(4) Process concerning the recommendation system:

The calculation process of the degree of similarity used when recommending sightseeing spots to users and the filtering process by means of priority evaluation items set by users are conducted at the backend. By having users register their preferences and select priority evaluation items when choosing recommendation conditions, users are able to receive recommendations. The conceptual diagram concerning this process is shown in Figure 7. Regarding the evaluation information of sightseeing spots and user preferences (or group preferences) accumulated in the database, the degree of similarity will be calculated using Equation (8) shown in Section 3.4.3. Furthermore, the sightseeing spot information and evaluation values of the top 20 in similarity will be selected, sorted (filtered) according to the value of priority evaluation items, and the top 10 sightseeing spots will be displayed as recommendation results.

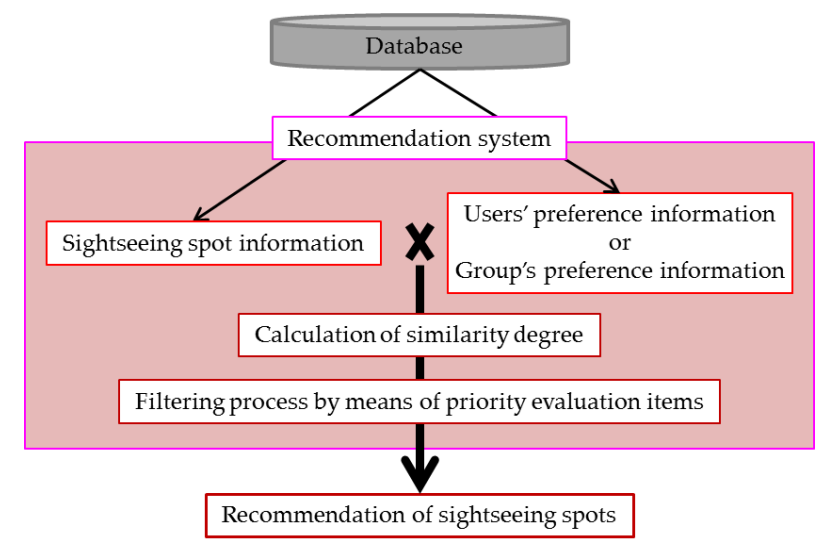

Figure 7. Conceptual diagram concerning the recommendation system.

\subsection{System Interface}

The system has two types of interfaces: the PC screen and mobile device screen for users (Figure 8), and the PC screen for the administrator. In the latter, the "membership number", "ID", "age" and "gender" of all users can be checked from a list. Furthermore, regarding users that have registered using the SNS link, the ID item will list either "Facebook" or "Twitter". Additionally, due to the simplification of user management using GUI (Graphic User Interface), procedures such as the deletion of unauthorized users can be done without depending on the IT literacy of the administrator. 


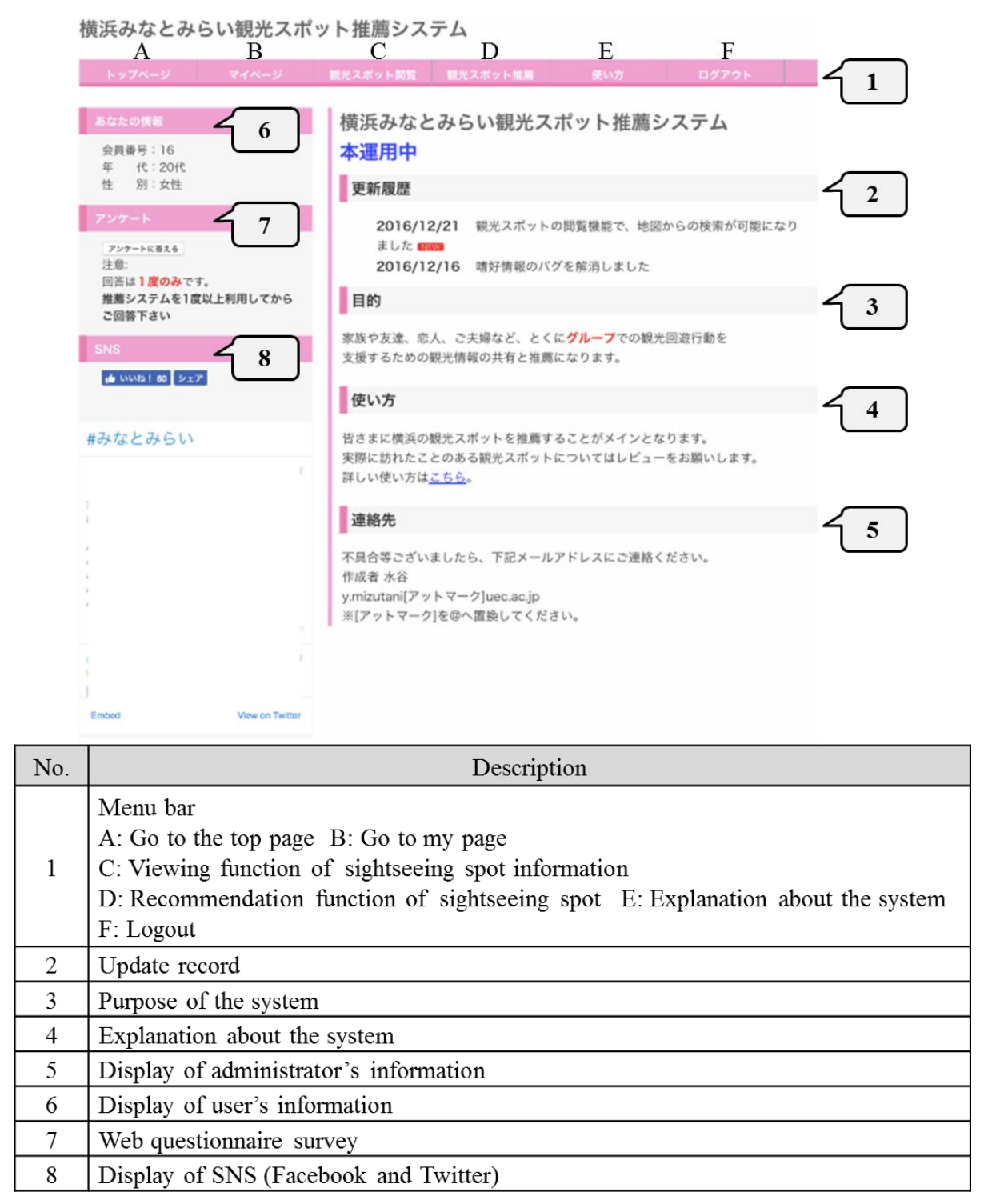

Figure 8. User's PC screen and explanation of each function.

\section{Operation}

\subsection{Sightseeing Spot Data}

In order to enable the use of functions right after the operation starts, it is necessary to gather sightseeing spot information beforehand. Therefore, 180 sightseeing spot information items in the social recommendation GIS developed by Ikeda et al., 2014 [29], were gathered, edited by referring to the travel review site, 4travel.jp [30], and accumulated in the system in advance. Additionally, when using the recommendation function of sightseeing spots, evaluation values concerning each sightseeing spot are needed. Therefore, the evaluation values were updated by referring to the aforementioned 4travel.jp [30]. When doing so, the number of evaluators in the same website is recorded according to each sightseeing spot. This is used as a parameter for the recalculation of new evaluation values when a user evaluated a sightseeing spot. However, if the number of evaluators is extremely low, the evaluation values obtained from the aforementioned preceding study are used, and the evaluators are each counted as one person. Referring to Ikeda et al., 2014 [29], Fujita et al., 2016 [8], and Zhou et al., 2016 [16], the system categorized all sightseeing spots into six categories including "food and drink", 
"shopping", "amusement parks and parks", "famous and historical sights", "art and historic museums" and "others (events, etc.)".

\subsection{User Assumption}

Those who are planning a trip within the operation target area, those who have visited the operation target area, as well as those living within the operation target area are assumed users of the system. Regarding those planning a sightseeing trip within the operation target area, it is assumed that they will gather information concerning sightseeing spots they are interested in by using the recommendation function of sightseeing spots and obtain detailed sightseeing spot information by means of the viewing function of sightseeing spot information. Regarding those who have visited or are living within the operation target area, they are encouraged to evaluate the sightseeing spots they have visited. Additionally, it is expected that such users will also utilize the viewing function of sightseeing spot information and the recommendation function of sightseeing spots to obtain the information concerning new places they have never visited before.

\subsection{Operation}

\subsubsection{Operation Overview}

The operation of the system was conducted over a period of four weeks with those inside and outside the operation target area. Whether inside or outside the operation target area, the operation of the system was advertised using the website of the authors' lab, as well as Twitter and Facebook. Additionally, the tourism department of Kanagawa Prefecture and Yokohama City in addition to the Yokohama Convention and Visitors Bureau (Yokohama City Tourism Association) supported the present study by distributing pamphlets and operating manuals.

Users register when using the system for the first time. User registration can be done either by registering an ID and password or by logging in to external SNS. For both methods excluding the use of Facebook, preferences are also registered in addition to "gender" and "age". If users register with Facebook, information concerning "gender" and "age", which is registered with Facebook, will be received and registered. After completing the registration, users will automatically go to the top page, and the use of functions within the system will be made available. Group registration will be also available from my page, and this will enable the use of the recommendation function of sightseeing spots as a group. Moreover, this made it possible to change user information, as well as preferences through my page, and this will allow users to receive sightseeing spot recommendations that meet their preferences.

\subsubsection{Management of Submitted Information by Administrators during the Operation}

Every user's submissions of information and image files are all accumulated as data in the database of the system. Administrators manage users and check submitted information using a list screen designed especially for the purpose. Administrators can take the measure of suspending accounts of users who have made inappropriate transmissions or behaved inappropriately, and if by any chance an inappropriate submission is made, administrators can delete the submission with just one click. Due to these features, there is no need for administrators to search to see whether or not inappropriate submissions of information have been made within the system; therefore, their burden can be lessened.

\subsubsection{Operation Results}

Users of the system are shown in Table 1. The system has a total of 52 users with 32 male and 20 female users. Regarding age groups, there are many male and female users in their 20s making up $46 \%$ of the total. Subsequently, those in their 40 s were $15 \%$; those in their 50 s and under 20 were 12\%; those in their 30 s were $10 \%$; and those in their 60 s and above were $6 \%$. Only eight of the users logged 
in to the system using external SNS. At the end of the operation period, a total of 19 users with 8 male and 11 female users (37\% of the total) registered a group.

There were 24 sightseeing spots ( $13 \%$ of all sightseeing spots) that had been newly evaluated by users, and these evaluation values were updated. By using the system over a long period, it can be expected that the number of evaluations on sightseeing spots will increase.

Table 1. Breakdown of system users and web questionnaire survey respondents.

\begin{tabular}{cccccccc}
\hline Age Groups of Users & $\mathbf{1 0 - 1 9}$ & $\mathbf{2 0 - 2 9}$ & $\mathbf{3 0 - 3 9}$ & $\mathbf{4 0 - 4 9}$ & $\mathbf{5 0 - 5 9}$ & $\mathbf{6 0 -}$ & Total \\
\hline $\begin{array}{c}\text { Number of users } \\
\text { Number of web questionnaire }\end{array}$ & $6(1)$ & $\mathbf{2 4}(12)$ & $5(2)$ & $8(2)$ & $6(2)$ & $3(0)$ & $52(19)$ \\
survey respondents & 1 & 10 & 4 & 8 & 6 & 3 & 32 \\
Valid response rate (\%) & 16.7 & 41.6 & 80.0 & 100.0 & 100.0 & 100.0 & 61.5 \\
\hline
\end{tabular}

Note: numerals in ( ) are those who registered groups.

\section{Evaluation}

After the end of the operation, a web questionnaire survey and access analysis of users' log data were conducted in order to evaluate the system developed in the present study.

\subsection{Evaluation Based on Web Questionnaire Survey}

\subsubsection{Overview of the Web Questionnaire Survey}

Along with the purpose of the present study, a web questionnaire survey was implemented in order to conduct an (1) evaluation concerning the use of the system and an (2) evaluation concerning the functions of the system. The web questionnaire survey was conducted for one week after the start of the operation. Table 1 also shows an overview of the web questionnaire survey. As shown in Table 1, 32 out of 52 users submitted their web questionnaire survey, and the valid response rate was $62 \%$.

\subsubsection{Evaluation Concerning the Use of the System}

(1) Evaluation of suitability with the information acquisition method for sightseeing spots:

Regarding information acquisition methods for sightseeing spots (multiple answers allowed), $72 \%$ were PCs, $44 \%$ were mobile devices, $47 \%$ were guidebooks and $16 \%$ were others (pamphlets and flyers). Therefore, it was made evident that many users obtain sightseeing information from the Internet using PCs and mobile devices in addition to using printed mediums such as guidebooks. This also made it clear that the system, which obtains sightseeing spot information using PCs and mobile devices, is effective.

(2) Evaluation focusing on the utilization state of the system:

Regarding the devices used by users for the system, $72 \%$ were PCs, $25 \%$ were smartphones and $3 \%$ were tablets. Therefore, it was made evident that the system was mainly used on PCs. The number of users who used external SNS login remained at $31 \%$. This is because the login function connected to external SNS can only be used by SNS users.

\subsubsection{Evaluation Concerning the Functions of the System}

(1) Evaluations for each function, as well as the whole system:

The evaluation results for each function, excluding the recommendation function of sightseeing spots, and the entire system are shown in Figure 9. Regarding the convenience of external SNS login, $78 \%$ answered "I think so" or "I somewhat think so", 16\% answered "neither" and 6\% answered 
"I don't think so". Therefore, as previously pointed out, because the login function connected to external SNS can only be used by SNS users, it can be said that those who are not SNS users do not recognize its convenience. Regarding the simplicity of group registrations, though $54 \%$ did not answer, $37 \%$ answered "I think so" or "I somewhat think so", $9 \%$ answered "neither" and 3\% answered "I don't think so". Therefore, though the group registration function is not so often used, those who used the function think it to be easy to use.

\section{Convenience of external SNS login}

Simplicity of group registrations

Simplicity of evaluation (review) submitting

Suitability of evaluation items for sightseeing spots

Suitability of evaluation items for preferences

Usefulness of the system when sightseeing

I think so $\square$ I think so $\square$ Neither $\square$ I don't think so $\square$ I don't think so at all $\square$ I didn't do it

Figure 9. Evaluation of the entire system Note: "simplicity of group registration", "simplicity of evaluation (review) submitting" and "suitability of evaluation items for sightseeing spots" include the option of “I didn't do it.

Regarding the simplicity of evaluation (review) submitting, though $66 \%$ did not answer, $25 \%$ answered "I think so" or "I somewhat think so" and 9\% answered "neither". For the suitability of evaluation items for sightseeing spots, though $66 \%$ did not answer, $32 \%$ answered "I think so" or "I somewhat think so" and 3\% answered "neither". Therefore, though the evaluation function of sightseeing spot is not often used, it can be said that the function is easy to use for those who have used it and that the evaluation items set in advance are suitable. Regarding the suitability of evaluation items for preferences, as $88 \%$ answered "I think so" or "I somewhat think so", it can be said that the evaluation items set in advance were suitable.

Regarding the usefulness of the system when sightseeing, all users answered "I think so" or "I somewhat think so". Because the system is highly useful when sightseeing as indicated by the results above, it can be expected that users will more fully use each function by continuously operating the system. Additionally, the group registration function and evaluation function of sightseeing spots in the system were hardly used during the operation period. Because the system was operated just for four weeks and the user did not fully utilize these two functions during the short operation period, these functions may be used more often by the continuous operation of the system, and this may advance the usefulness of the system when sightseeing.

(2) Detailed evaluations for the recommendation function of sightseeing spots:

Evaluation results for the recommendation function of sightseeing spots, which is the system's original function, are shown in Figure 10. For the suitability of the number of recommended sightseeing spots (10 items), as all users answered "I think so" or "I somewhat think so", it was made evident that recommending multiple sightseeing spots was suitable. Regarding the convenience of sightseeing spot category choices, a high percentage of $94 \%$ answered "I think so" or "I somewhat think so", so it can be said that the category selection when getting a recommendation was effective. 
For the convenience of selecting priority evaluation items, the results were good with $97 \%$ answering "I think so" or "I somewhat think so". Additionally, regarding the suitability of recommended sightseeing spots by means of selecting priority evaluation items, $84 \%$ answered "I think so" or "I somewhat think so". From these results, it can be said that the selection of evaluation items to prioritize when the system makes a recommendation was effective.

Regarding the suitability of sightseeing spots recommended by group registration, the evaluation was somewhat lower than other questions with a result of $82 \%$ answering "I think so" or "I somewhat think so". As previously mentioned, the group registration function was hardly used during the operation period. However, if the group registration is more often used by the continuous operation of the system, this may improve the suitability of sightseeing spots recommended to groups. Additionally, for the satisfaction of the sightseeing spots recommended, the results were very high with $94 \%$ answering "I think so" or "I somewhat think so". Therefore, the method of the system, in which the preferences of all users within the group are reflected in the recommended sightseeing spots, can be considered to be highly effective.

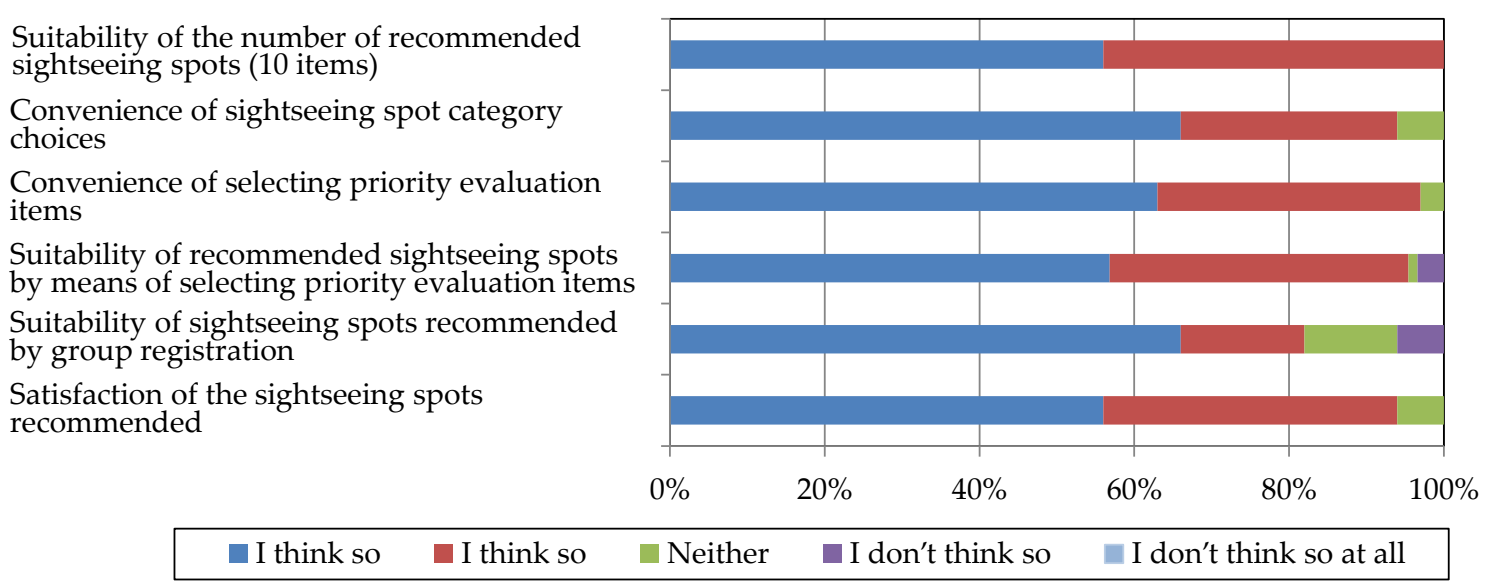

Figure 10. Detailed evaluation concerning the recommendation function of sightseeing spots.

\subsection{Evaluation Based on Access Analysis}

In the present study, an access analysis was conducted using the users' log data during the operation period. This analysis was conducted using Google Analytics, which is a web access analysis service provided by Google. A PHP program with the analysis code made using Google Analytics was created, and for the target websites for the access analysis, the access log was obtained by scanning the PHP program made for the access analysis of the program in each page within that website.

The access method to the system is shown in Table 2. There is hardly any difference in the use of PCs and mobile devices as an access method. This is because smartphones are now often used as an easy way to obtain information. Therefore, the system design, which was made to eliminate the differences in obtainable information depending on the type of device and to make the system available to all types of devices, can be considered effective.

Table 2. Access methods.

\begin{tabular}{ccc}
\hline Access Method & Number of Sessions & Percentage (\%) \\
\hline PC & 81 & 50.0 \\
Smartphone & 80 & 49.4 \\
Tablet & 1 & 0.6 \\
\hline
\end{tabular}


The top 10 number of page visits is shown in Table 3. As it is made clear in Table 3, except for the top page and how to use page, the sightseeing spot recommendation page has the most visits, and it is also evident that the system is being used according to the purpose of the present study, which is to support the sightseeing activities of users. However, as few users viewed the group registration page, it cannot be said that the system was used to the fullest extent. This may be because the operation period was limited and only a few actually used the system as a group. Additionally, the user information edit page also had a low number of visits. Therefore, it is evident that the preferences of users hardly changed in a short period of time, and most users did not change their preference registration after the initial registration. However, by conducting a long-term operation of the system, it is expected that the preferences of users will change and more users will change their preference information through the user information edit page.

Table 3. Number of visits according to page (top 10).

\begin{tabular}{cccc}
\hline Rank & Page Name & Number of Page Visits & Percentage (\%) \\
\hline 1 & Top page & 265 & 34.9 \\
2 & How to use page & 66 & 8.7 \\
3 & Sightseeing spot recommendation page (condition entry) & 54 & 7.1 \\
4 & Login page & 46 & 6.0 \\
5 & Sightseeing spot information viewing page (list) & 45 & 5.9 \\
6 & My page & 44 & 5.8 \\
7 & Sightseeing spot recommendation page (results list) & 39 & 5.1 \\
8 & User information edit page & 24 & 3.2 \\
9 & Group registration page & 20 & 2.6 \\
10 & User registration page & 19 & 2.5 \\
\hline
\end{tabular}

\subsection{Extraction of Improvement Measures}

The issues concerning the system were extracted based on the results of the web questionnaire survey, as well as the access analysis of users' log data, and they are summarized below.

(1) Adding and updating of sightseeing spot information by users:

Though the system had prepared sightseeing spot information in advance, in order to operate on a long-term basis, the sightseeing spot information should be updated when necessary. Therefore, a function where users can add and update information is needed.

(2) Implementing a routing function:

In the system, sightseeing spots that meet the preferences of both individual users and groups can be recommended. However, the system only recommends sightseeing spots and provides detailed information. Therefore, in order to effectively support the sightseeing activities of users, it is necessary to implement a routing function from major stations and current locations to destinations.

(3) Improving the group registration function:

In the system, users can register groups. However, during the operation period, only half of those who answered the web questionnaire survey had used this group registration function. Therefore, it is necessary to make the group registration easier to use.

\section{Conclusions}

In the present study, after designing and developing the system (Sections 3 and 4), the operation (Section 5), as well as the evaluation and extraction of improvement measures (Section 6) were conducted. The present study can be summarized as the following three points.

(1) In order to support sightseeing activities by reflecting the changes of priority conditions concerning the sightseeing spots, as well as the different preferences within the groups when 
recommending sightseeing spots, a system that integrated the Web-GIS, the pairing system, the evaluation system and the recommendation system was designed and developed. By doing so, the reduction of the burden when obtaining information, the adaption to changes in needs when sightseeing and the unification of the preferences of all users within a group were made possible. The central part of Yokohama City in Kanagawa Prefecture, Japan, was chosen as the operation target area, and the system operation and evaluation were conducted.

(2) The operation of the system was conducted over a period of four weeks targeting those inside and outside the operation target area, and a web questionnaire survey was conducted towards all users. Based on the results of the web questionnaire survey, the usefulness of the system when sightseeing was high, and the further use of each function can be expected by continuous operation. Especially for the group registration function and the evaluation function of sightseeing spots, there is a possibility that they will be used more fully by the continuous operation of the system, and this will improve the usefulness of the system when sightseeing. The recommendation function of sightseeing spots, which is an original function of the system, has received mainly good ratings, and if the group registration function is used more often, there is a possibility that the suitability of sightseeing spots recommended to groups will improve.

(3) From the results of the access analysis of users' log data, it is evident that the system has been used by different types of devices, just as it was designed for, and that the system has been used according to the purpose of the present study, which is to support the sightseeing activities of users. However, only a few used the group registration function or changed their preferences after the initial registration. Such issues may be improved by the long-term operation of the system. Therefore, in the next step of the present study, it is necessary to inspect this point by the even more long-term operation of the system.

As future study projects, the improvement of the system based on the results in Section 6.3, as well as the enhancement of the significance of using the system by gaining more results in other urban sightseeing areas can be raised. Furthermore, based on the improved system in the present study, the authors have a plan to newly develop the navigation system and commercialize it in cooperation with private companies in the related fields.

Acknowledgments: In the operation of the sightseeing spot recommendation system and the web questionnaires survey of the present study, enormous cooperation was received from those mainly in the Kanto region such as Kanagawa Prefecture and Tokyo Metropolis. We would like to take this opportunity to gratefully acknowledge them.

Author Contributions: Yuri Mizutani design, develop and operate the sightseeing spot recommendation system in the present study. She also initially drafted the paper. Kayoko Yamamoto carried out background work, and evaluates the system. All authors contributed to write up and review, and approved the paper manuscript.

Conflicts of Interest: The authors declare no conflict of interest.

\section{References}

1. Ishizuka, J.; Suzuki, Y.; Kawagoe, K. Method for Searching for Similarities in Data on Movement Paths, Designed to Support Sightseeing in Kyoto. In The Special Interest Group Technical Reports of Information Processing Society of Japan, CVIM, "Computer Vision and Image Media"; Information Processing Society of Japan: Tokyo, Japan, 2007; Volume 2007, pp. 17-23.

2. Kurata, Y. Introducing a Hot-Start Mechanism to a Web-based Tour Planner CT-Planner and Increasing its Coverage Areas. In Proceedings of the Geographic Information Systems Association of Japan, Hiroshima, Japan, 13-14 October 2012; Volume 21.

3. Hidenori, K. Efforts to Spread Standard Tags in Hokkaido Tourist Information, and the Development of Kyun-Channel. J. Digit. Pract. 2012, 3, 272-280.

4. Sasaki, J.; Uetake, T.; Horikawa, M.; Sugawara, M. Development of Personal Sightseeing Support System during Long-Term Stay. In Proceedings of the 75th National Convention of IPSJ, Sendai, Japan, 6-8 March 2013; pp. 727-728. 
5. Fujitsuka, T.; Harada, T.; Sato, H.; Takadama, K. Recommendation system for Sightseeing Plan using Pattern Mining to Evaluate Time Series Action. In Proceedings of the Annual Conference on Society of Instrument and Control Engineering, Sapporo, Japan, 9-12 September 2014; SS12-10. pp. 802-807.

6. Ueda, T.; Ooka, R.; Kumano, K.; Tarumi, H.; Hayashi, T.; Yaegashi, M. Sightseeing Support System to Support Generation/Sharing of Sightseeing Information. In The Special Interest Group Technical Reports of IPSJ: Information System and Social Environment (IS); Information Processing Society of Japan: Tokyo, Japan, 2015; 2015-IS-131(4); pp. 1-7.

7. Okuzono, M.; Hokota, M.; Hirano, H.; Masuko, S.; Hoshino, J. Recommendation System of Sightseeing Area for Groups. In The Special Interest Group Technical Reports of IPSJ: Human Computer Interaction (HCI); Information Processing Society of Japan: Tokyo, Japan, 2015; 2015-HCI-162(19); pp. 1-8.

8. Fujita, T.; Yamamoto, K. Development of Dynamic Real-Time Navigation System. Int. J. Adv. Comput. Sci. Appl. 2016, 7, 116-130. [CrossRef]

9. Kurashima, T.; Iwata, T.; Irie, G.; Fujimura, K. Travel Route Recommendation using Geotags on Photo Sharing Service. In Technical Report of the Institute of Electronics, Information and Communication Engineers, LOIS, "Life Intelligence and Office Information Systems"; Institute of Electronics, Information and Communication Engineers: Tokyo, Japan, 2010; Volume 109, pp. 55-60.

10. Canneyt, S.V.; Schockaert, S.; Olivier, V.L.; Dhoedt, B. Time-Dependent Recommendation of Tourist Attractions using Flickr. In Proceedings of the 24th Benelux Conference on Artificial Intelligence, Maastricht, The Netherlands, 25-26 October 2012; pp. 255-262.

11. Batet, M.; Moreno, A.; Sánchez, D.; Isern, D.; Valls, A. Turist @: Agent-Based Personalised Recommendation of Tourist Activities. Expert Syst. Appl. 2012, 39, 7319-7329. [CrossRef]

12. Uehara, H.; Shimada, K.; Endo, T. Sightseeing Location Recommendation using Tourism Information on the Web. In Technical Report of the Institute of Electronics, Information and Communication Engineers, NLC, "Natural language Understanding and Models of Communication"; Institute of Electronics, Information and Communication Engineers: Tokyo, Japan, 2012; Volume 112, pp. 13-18.

13. Shaw, B.; Shea, J.; Sinha, S.; Hogue, A. Learning to Rank for Spatiotemporal Search. In Proceedings of the sixth ACM International Conference on Web Search and Data Mining, Rome, Italy, 4-8 February 2012; pp. 717-726.

14. Zhou, J.; Yamamoto, K. Development of the System to Support Tourists' Excursion Behavior Using Augmented Reality. Int. J. Adv. Comput. Sci. Appl. 2016, 7, 197-209. [CrossRef]

15. Yu, C.; Chang, H. Personalized Location-Based Recommendation Services for Tour Planning in Mobile Tourism Applications. In Proceedings of the 10th International Conference on E-Commerce and Web Technologies, Linz, Austria, 1-4 September 2009; pp. 38-49.

16. Noguera, J.M.; Barranco, M.J.; Segura, R.J.; Martínez, L. A Mobile 3D-GIS Hybrid Recommender System for Tourism. Inf. Sci. 2012, 215, 37-52. [CrossRef]

17. Braunhofer, M.; Elahi, M.; Ricci, F. Context-Aware Places of Interest Recommendations for Mobile Users, Design, User Experience, and Usability. Theory Methods Tools Pract. Lect. Notes Comput. Sci. 2011, 6769, 531-540.

18. Ye, M.; Yin, P.; Lee, W.; Lee, D. Exploiting Geographical Influence for Collaborative Point-of-Interest Recommendation. In Proceedings of the 34th international ACM SIGIR conference on Research and Development in Information Retrieval, Beijing, China, 24-28 July 2011; pp. 325-334.

19. Ying, J.J.; Lu, E.H.; Kuo, W.; Tseng, V.S. Urban Point-of-interest Recommendation by Mining User Check-in Behaviors. In Proceedings of the ACM SIGKDD International Workshop on Urban Computing, Beijing, China, 12-16 August 2012; pp. 63-70.

20. Bao, J.; Zheng, Y.; Mokbel, M.F. Location-Based and Preference-Aware Recommendation using Sparse Geo-Social Networking Data. In Proceedings of the 20th International Conference on Advances in Geographic Information Systems, Redondo Beach, CA, USA, 7-9 November 2012; pp. 199-208.

21. Yuan, Q.; Cong, G.; Ma, Z.; Sun, A.; Magnenat-Thalmann, N. Time-Aware Point-of-Interest Recommendation. In Proceedings of the 36th International ACM SIGIR Conference on Research and Development in Information Retrieval, Dublin, Ireland, 28 July-1 August 2013; pp. 363-372.

22. Liu, X.; Liu, Y.; Aberer, K.; Miao, C. Personalized Point-of-Interest Recommendation by Mining Users' Preference Transition. In Proceedings of the 22nd ACM International Conference on Information \& Knowledge Management, San Francisco, CA, USA, 27 October-1 November 2013; pp. 733-738. 
23. Yanagisawa, T.; Yamamoto, K. Study on Information Sharing GIS to Accumulate Local Knowledge in Local Communities. Theory Appl. GIS 2012, 20, 61-70.

24. Nakahara, H.; Yanagisawa, T.; Yamamoto, K. Study on a Web-GIS to Support the Communication of Regional Knowledge in Regional Communities: Focusing on Regional Residents' Experiential Knowledge. J. Socio-Inform. 2012, 1, 77-92.

25. Yamada, S.; Yamamoto, K. Development of Social Media GIS for Information Exchange between Regions. Int. J. Adv. Comput. Sci. Appl. 2013, 4, 62-73. [CrossRef]

26. Okuma, T.; Yamamoto, K. Study on a Social Media GIS to Accumulate Urban Disaster Information: Accumulation of Disaster Information during Normal Times for Disaster Reduction Measures. J. Socio-Inform. 2013, 2, 49-65.

27. Murakoshi, T.; Yamamoto, K. Study on a Social Media GIS to Support the Utilization of Disaster Information: For Disaster Reduction Measures from Normal Times to Disaster Outbreak Times. J. Socio-Inform. 2014, 3, 17-30.

28. Yamamoto, K.; Fujita, S. Development of Social Media GIS to Support Information Utilization from Normal Times to Disaster Outbreak Times. Int. J. Adv. Comput. Sci. Appl. 2015, 6, 1-14. [CrossRef]

29. Ikeda, T.; Yamamoto, K. Development of Social Recommendation GIS Tourist Spots. Int. J. Adv. Comput. Sci. Appl. 2014, 5, 8-21. [CrossRef]

30. 4travel.jp. Available online: http:/ / 4travel.jp/ (accessed on 14 September 2017).

31. KAYAK. Available online: https://www.kayak.co.jp/ (accessed on 14 September 2017).

32. TripAdvisor. Available online: https://www.tripadvisor.jp/ (accessed on 14 September 2017).

33. Ohki, M.; Murofushi, T. A Proposal of the Group Decision Making Analysis Using “Distance-Adjusted Covariates. J. Jpn. Soc. Fuzzy Theory Intell. Inform. 2013, 25, 842-852.

34. Jannach, D.; Zanker, M.; Felfernig, A.; Friedrich, G. Recommender Systems: An Introduction; Cambridge University Press: Cambridge, UK, 2011.

35. Kamishima, T. Algorithms for recommender systems (2). Trans. Jpn. Soc. Artif. Intell. 2008, 23, 89-103.

(C) 2017 by the authors. Licensee MDPI, Basel, Switzerland. This article is an open access article distributed under the terms and conditions of the Creative Commons Attribution (CC BY) license (http:/ / creativecommons.org/licenses/by/4.0/). 